\title{
Species Classification of Aquatic Plants using GRNN and ANFIS
}

\author{
S. Abirami \\ Annamalai University \\ Dept. of Computer Science \\ and Engineering, \\ Chidambaram - 608001
}

\author{
V. Ramalingam \\ Annamalai University \\ Dept. of Computer Science \\ and Engineering, \\ Chidambaram - 608001
}

\author{
S. Palanivel \\ Annamalai University \\ Dept. of Computer Science \\ and Engineering, \\ Chidambaram - 608001
}

\begin{abstract}
This work presents a method for plant species identification using the images of flowers. It focuses on the stable features of flowers such as color, texture and shape. K-means clustering is used to extract the color features. Texture segmentation is done using texture filters. Edge detectors are used to trace the boundary of the image and hence the shape features. Color, texture and shape features are extracted from 400 images of flowers. Classification of plants into dry land plants and aquatic plants, the aquatic plant species into wet and marsh aquatic plants, wet aquatic plants into iridaceae and epilobium family and marsh aquatic plants into malvaceae and onagraceae family, the iridaceae family into babiana and crocus species, the family epilobium into canum and hirsutum, the family malvaceae into mallow and pavonia, the family onagraceae into fuschia and ludwigia species are done using Generalized Regression Neural Network (GRNN) and Adaptive Neural Fuzzy Inference System (ANFIS) classifiers.
\end{abstract}

\section{Keywords}

K-means clustering, Texture filters, Cross fold validation, Pattern Recognition tools.

\section{INTRODUCTION}

The identification and classification of plants is a much probed area in the field of research and development in botanical science. A number of manual and computerized techniques have evolved in the past years. Manual classification is a very time consuming process. With the advent of the digital world, the digital libraries and algorithms serve as premier catalytic agents in enhancing plant identification and thereby botanical research. Most of the computer aided research algorithms use the features of plant leaves as key factors for plant identification. However, the flowers of plants also encompass enormous invaluable information on the plant family. This paper tries to recognize the known plant species by extracting salient features of the flowers. Identification of these plants can develop a better understanding of ecological relationships and helps in the better understanding of plants for its potential use [4].

\subsection{Literature Review}

A content based image retrieval system has been presented for house plant identification. Feature extraction is applied after segmenting the image using max-flow min-cut technique. The accuracy has gone up to $73 \%$ when a subset of 132 well segmented plant images was considered [1]. Plant species identification based on neural network focuses on the features of leaf, such as the geometrical features of shape and texture features of venation. In the testing phase, 144 leaf images of 15 kinds of plants were collected for the test. The classification rate using self-organizing map neural network was $88.4 \%$ [2].

Content based leaf image retrieval (CBLIR) using shape, color and texture features paper proposes an efficient computer-aided plant image retrieval method based on plant leaf images. Log Gabor wavelet was applied to the input image for texture feature extraction. Results on a database of 500 plant images show $97.9 \%$ of retrieval efficiency [3]. Recognition of plants by digital image of leaves and neutral network has provided optimum results. The accuracy is about $80 \%$ [5].

Tools for texture/color based search of images describe the work on developing an image segmentation algorithm which is useful for processing large and diverse collections of image data [6]. Machine learning techniques for ontology based leaf classification proposes an integrated approach for an ontologybased leaf classification system [7].

By analysing local brightness, color, and texture, boundaries in natural scenes are detected using local image measurements. Features are formulated according to characteristic changes in brightness, color, and texture associated with natural boundaries [8]. The shape and texture features of the leaves of broadleaved trees constitute a synthetic feature vector to realize automatic classification of broad-leaved trees. Using probabilistic neural networks ( $\mathrm{PNN})$, the correct recognition rate reached $98.3 \%$ [9].

SVM-BDT PNN and Fourier Moment Technique for Classification of Leaf Shape presents three techniques of plant classification based on the shape of leaves [10]. Shape and vein extraction of plant leaf images using Fourier and B-spline modeling extracted the shape and vein of leaves. It provides the comparison between Fourier descriptor and Hough transform [12]. For the leaf contour classification, a scaled CCD code system was proposed to categorize the basic shape and margin type of a leaf by using the similar taxonomy principle adopted by the botanists. Extreme learning machine to plant species identification, a recently developed machine learning algorithm was used to classify the plant species through plant leaf Gabor texture feature [14].

\section{METHODOLOGY}

Flower image acquisition and feature extraction are discussed in the following subsections.

\subsection{Flower Image Acquisition}

400 flower images are acquired from the database www.csdl.tamu.edu/flora. These flower images are RGB color images.

\subsection{Feature Extraction}

Images are analyzed using color, texture and shape features. 


\subsubsection{Color features}

Color based segmentation using k-means clustering is used to extract the color features. In this technique, the colors are segmented in an automated fashion using the $\mathrm{L}^{*} \mathrm{a}^{*} \mathrm{~b}^{*}$ color space and k-means clustering. Initially, the flower image is read. Then the image is converted from RGB color space to $L^{*} a * b *$ color space. The $L^{*} a * b *$ enables to quantify the visual differences. The $\mathrm{L} * \mathrm{a} * \mathrm{~b} *$ color space is derived from the CIE XYZ tri-stimulus values. The $\mathrm{L}^{*} \mathrm{a}^{*} \mathrm{~b}^{*}$ space consists of a luminosity layer ' $\mathrm{L}$ ', chromaticity layer ' $\mathrm{a}$ ' ' indicating where color falls along red-green axis and chromaticity layer ' $b$ *' indicating where the color falls along the blue-yellow axis. All color information are in the ' $a$ *' and ' $b$ *' layers. The colors in ' $a * b$ ' space are classified using k-means clustering. Clustering is a way to separate groups of objects.

$\mathrm{K}$-means clustering treats each object as having a location in space. It partitions an image into clusters such that closely related objects constitute a cluster and are different from objects in another cluster. K-means clustering requires the specification of number of clusters to be partitioned and a distance metric to quantify how close two objects are to each other. Since, the color information exists in the ' $a * b^{*}$ ' space, the objects are pixels with ' $a{ }^{*}$ ' and ' $b$ *' values. $\mathrm{K}$-means is used to cluster the objects into three clusters using the Euclidean distance metric. For every object, k-means returns an index corresponding to a cluster. The cluster center output from k-means is used for the classification. Sample data for color feature is shown in table 1 .

Table 1: Sample data showing color features of the aquatic plant family Iridaceae

\begin{tabular}{|c|c|c|c|c|c|}
\hline $\begin{array}{l}\text { S. } \\
\text { no }\end{array}$ & species & $\begin{array}{c}\text { Mean } \\
\text { cluster } \\
\text { center }\end{array}$ & $\begin{array}{c}\text { Mean } \\
\text { cluster } \\
\text { center }\end{array}$ & $\begin{array}{c}\text { Standa } \\
\text { rd } \\
\text { deviati } \\
\text { on } \\
\end{array}$ & $\begin{array}{c}\text { Standar } \\
\text { d } \\
\text { deviatio } \\
n\end{array}$ \\
\hline 1. & $\begin{array}{l}\text { Albidu } \\
\mathrm{m}\end{array}$ & $\begin{array}{l}116.90 \\
63\end{array}$ & $\begin{array}{l}147.33 \\
57\end{array}$ & $\begin{array}{l}10.561 \\
5\end{array}$ & 18.3332 \\
\hline 2. & $\begin{array}{l}\text { Aphyll } \\
\text { a }\end{array}$ & $\begin{array}{l}114.33 \\
70\end{array}$ & $\begin{array}{l}129.71 \\
99\end{array}$ & $\begin{array}{l}14.733 \\
6\end{array}$ & $\begin{array}{l}255.905 \\
2\end{array}$ \\
\hline 3. & $\begin{array}{l}\text { August } \\
\text { ifolium }\end{array}$ & $\begin{array}{l}118.13 \\
75\end{array}$ & $\begin{array}{l}136.55 \\
98\end{array}$ & 9.7361 & 12.0529 \\
\hline 4. & Crocus & $\begin{array}{l}137.33 \\
72\end{array}$ & $\begin{array}{l}121.26 \\
77\end{array}$ & $\begin{array}{l}18.583 \\
0\end{array}$ & 35.9861 \\
\hline 5. & Dietes & $\begin{array}{l}138.35 \\
50\end{array}$ & $\begin{array}{l}141.41 \\
93\end{array}$ & 8.9554 & 46.0834 \\
\hline 6. & $\begin{array}{l}\text { Crocus } \\
1\end{array}$ & $\begin{array}{l}127.49 \\
13\end{array}$ & $\begin{array}{l}161.78 \\
65\end{array}$ & 1.2008 & 0.1494 \\
\hline 7. & $\begin{array}{l}\text { Gladio } \\
\text { li }\end{array}$ & $\begin{array}{l}166.93 \\
37\end{array}$ & $\begin{array}{l}159.42 \\
99\end{array}$ & $\begin{array}{l}35.444 \\
3\end{array}$ & 29.2575 \\
\hline 8. & $\begin{array}{l}\text { Gladio } \\
\text { lus }\end{array}$ & $\begin{array}{l}134.76 \\
62\end{array}$ & $\begin{array}{l}143.61 \\
98\end{array}$ & $\begin{array}{l}25.097 \\
6\end{array}$ & 15.8819 \\
\hline 9. & $\begin{array}{l}\text { Tennes } \\
\text { see }\end{array}$ & $\begin{array}{l}134.66 \\
81\end{array}$ & $\begin{array}{l}143.68 \\
36\end{array}$ & $\begin{array}{l}15.115 \\
7\end{array}$ & 58.1917 \\
\hline 10 & $\begin{array}{l}\text { Tigrida } \\
\text { pavoni } \\
\text { a }\end{array}$ & $\begin{array}{l}117.04 \\
01\end{array}$ & $\begin{array}{l}141.23 \\
75\end{array}$ & $\begin{array}{l}11.076 \\
3\end{array}$ & 12.7901 \\
\hline
\end{tabular}

\subsubsection{Texture features}

Texture analysis refers to the characterization of regions in an image by their texture content. The goal of texture analysis is to quantify intuitive qualities such as rough, smooth, silky or bumpy as functions of the spatial variation in pixel intensities. The roughness or bumpiness refers to variations in their intensity values or gray levels. Texture analysis can be used to find the texture boundaries called texture segmentation. Texture analysis can be helpful when objects in an image are more characterized by their texture than by intensity, and traditional thresh-holding techniques cannot be used effectively. Texture filters are used to segment the image. The gray level cooccurrence matrix provides statistics used in the species identification [15]. A statistical method of examining texture that considers the spatial relationship of pixels is the gray level co-occurrence matrix, also known as the gray-level spatial dependence matrix. The GLCM functions characterize the texture of an image by calculating how often pairs of pixel with specific values and in a specified spatial relationship occur in an image, creating a GLCM, and then by extracting statistical measures from this matrix. To create GLCM, use the graycomatrix function. The graycomatrix function creates a gray level co-occurrence matrix by calculating how often a pixel with the intensity value $i$ occurs in a specific spatial relationship to a pixel with the value $\mathrm{j}$. By default, the spatial relationship is defined as the pixel of interest and the pixel to its immediate right, but you can specify other spatial relationships between the two pixels. Each element $(i, j)$ in the resultant GLCM is simply the sum of the number of times that the pixel with value $i$ occurred in the specified spatial relationship to a pixel with value $j$ in the input image. The number of gray levels in the image determines the size of the GLCM. The gray-level co-occurrence matrix can reveal certain properties about the spatial distribution of the gray levels in the texture image. The texture features extracted are energy, contrast, correlation, homogeneity and entropy. Sample data for texture features are shown in table 2.

Table 2: Sample data showing texture features of the aquatic plant family Iridaceae

\begin{tabular}{|l|l|l|l|l|l|l|}
\hline $\begin{array}{c}\text { S. } \\
\mathbf{N} \\
\mathbf{o}\end{array}$ & Species & $\begin{array}{c}\text { Contr } \\
\text {-ast }\end{array}$ & $\begin{array}{c}\text { Corre } \\
\text { l- } \\
\text { ation }\end{array}$ & $\begin{array}{c}\text { Ener } \\
\text { gy }\end{array}$ & $\begin{array}{c}\text { Homo } \\
\text { ge- } \\
\text { nity }\end{array}$ & $\begin{array}{l}\text { Entr } \\
\text { opy }\end{array}$ \\
\hline 1. & Albidum & 0.068 & 0.982 & 0.66 & 0.985 & 2.70 \\
& & 4 & 0 & 09 & 7 & 30 \\
\hline 2. & Aphylla & 0.094 & 0.979 & 0.63 & 0.983 & 2.67 \\
& & 9 & 90 & 2 & 10 \\
\hline 3. & $\begin{array}{l}\text { Augustif } \\
\text { olium }\end{array}$ & 0.065 & 0.985 & 0.57 & 0.987 & 3.32 \\
\hline 4. & Crocus & 0.240 & 0.860 & 0.68 & 0.950 & 2.79 \\
& & 3 & 2 & 80 & 2 & 42 \\
\hline 5. & Dietes & 0.102 & 0.982 & 0.60 & 0.983 & 3.08 \\
& & 3 & 6 & 74 & 6 & 51 \\
\hline 6. & Crocus1 & 0.085 & 0.962 & 0.55 & 0.970 & 3.71 \\
& & 8 & 2 & 93 & 3 & 35 \\
\hline 7. & Gladioli & 0.077 & 0.980 & 0.61 & 0.985 & 2.81 \\
& 8 & 5 & 53 & 1 & 59 \\
\hline 8. & Gladiolu & 0.038 & 0.976 & 0.71 & 0.990 & 2.75 \\
& s & 1 & 3 & 41 & 7 & 75 \\
\hline 9. & Tenness & 0.094 & 0.973 & 0.69 & 0.984 & 2.74 \\
& ee & 9 & 5 & 07 & 9 & 68 \\
\hline 10 & Tigrida & 0.109 & 0.971 & 0.60 & 0.973 & 3.16 \\
. & pavonia & 9 & 1 & 36 & 7 & 11 \\
& & & & & & \\
\hline
\end{tabular}

\subsubsection{Shape features}

The Sobel, Prewit, Roberts method finds edges using their approximation to the derivative. It returns edges at those points where the gradient of image is maximum. The mean distance 
transform for these three filters are extracted for classification. The distance transform is the distance from every pixel to the nearest non-zero valued pixel [16]. Sample data for shape feature is shown in table 3 .

Table 3: Sample data showing shape features of the aquatic plant family Iridaceae

\begin{tabular}{|l|l|l|l|l|}
\hline $\begin{array}{c}\text { s.n } \\
\text { o }\end{array}$ & \multicolumn{1}{|c|}{ species } & $\begin{array}{c}\text { Mean } \\
\text { distance } \\
\text { transfor } \\
\text { m of } \\
\text { sobel }\end{array}$ & $\begin{array}{c}\text { Mean } \\
\text { distance } \\
\text { transform } \\
\text { of prewitt }\end{array}$ & $\begin{array}{c}\text { Mean } \\
\text { distance } \\
\text { transform } \\
\text { of robert }\end{array}$ \\
\hline 1. & Albidum & 0.0684 & 0.6609 & 0.9857 \\
\hline 2. & Aphylla & 0.0949 & 0.6390 & 0.9832 \\
\hline 3. & $\begin{array}{l}\text { Augustif } \\
\text { olium }\end{array}$ & 0.0657 & 0.5722 & 0.9874 \\
\hline 4. & Crocus & 0.2403 & 0.6880 & 0.9502 \\
\hline 5. & Dietes & 0.1023 & 0.6074 & 0.9836 \\
\hline 6. & Crocus1 & 0.0858 & 0.5593 & 0.9703 \\
\hline 7. & Gladioli & 0.0778 & 0.6153 & 0.9851 \\
\hline 8. & $\begin{array}{l}\text { Gladiolu } \\
\text { s }\end{array}$ & 0.0381 & 0.7141 & 0.9907 \\
\hline 9. & $\begin{array}{l}\text { Tennesse } \\
\text { e }\end{array}$ & 0.0949 & 0.6907 & 0.9849 \\
\hline 10. & $\begin{array}{l}\text { Tigrida } \\
\text { pavonia }\end{array}$ & 0.1099 & 0.6036 & 0.9737 \\
\hline & & & & \\
\hline
\end{tabular}

\section{3. 'N' Folds Cross Validation of Data}

In $\mathrm{N}$ fold cross validation, first the training set is divided into $\mathrm{n}$ subsets of equal size. One subset is tested using the classifier trained on the remaining subsets. The cross-validation accuracy is the percentage of data which are correctly classified. It can prevent the over fitting problem [17]. In this study the four fold cross validation is applied for training and testing the GRNN and ANFIS classifier. In four fold cross validation, the training set is randomly divided into 4 disjoint sets namely fold1 (f1), fold2 (f2), fold3 (f3), fold4 (f4) Further these folds are formed with the following groups for training and test data preparation for image classification. Table 4 shows the four fold cross validation of data.

\begin{tabular}{|c|c|c|}
\hline $\begin{array}{c}\text { GROUP } \\
\text { NO. }\end{array}$ & TRAINING DATA & $\begin{array}{c}\text { TESTING } \\
\text { DATA }\end{array}$ \\
\hline 1 & $\mathrm{f} 1+\mathrm{f} 2+\mathrm{f} 3$ & $\mathrm{f} 4$ \\
\hline 2 & $\mathrm{f} 2+\mathrm{f} 3+\mathrm{f} 4$ & $\mathrm{f} 1$ \\
\hline 3 & $\mathrm{f} 3+\mathrm{f} 4+\mathrm{f} 1$ & $\mathrm{f} 2$ \\
\hline 4 & $\mathrm{f} 1+\mathrm{f} 2+\mathrm{f} 4$ & $\mathrm{f} 3$ \\
\hline
\end{tabular}

Table 4: Fourfold cross validation

\subsection{Classifiers}

\subsubsection{Generalized Regression Neural Network}

A generalized regression neural network (GRNN) is often used for function approximation. It has a radial basis layer and a special linear layer. It is similar to the radial basis network, but has a slightly different second layer. Here the nprod box shown above produces $S 2$ elements in vector $\mathbf{m} 2$. Each element is the dot product of a row of LW2,1 and the input vector $\mathbf{a} 1$, all normalized by the sum of the elements of $\mathbf{a} 1$. The first layer is just like that for newrbe networks. It has as many neurons as there are input/ target vectors in $\mathbf{P}$. Specifically, the firstlayer weights are set to $\mathbf{P}^{\prime}$. The bias $\mathbf{b} 1$ is set to a column vector of 0.8326/SPREAD. The user chooses SPREAD the distance an input vector must be from a neuron's weight vector - to be 0.5. Again, the first layer operates just like the newrbe radial basis layer described previously. Each neuron's weighted input is the distance between the input vector and its weight vector, calculated with dist. Each neuron's net input is the product of its weighted input with its bias, calculated with netprod. Each neuron's output is its net input passed through radbas. If a neuron's weight vector is equal to the input vector (transposed), its weighted input will be 0 , its net input will be 0 , and its output will be 1 . If a neuron's weight vector is a distance of spread from the input vector, its weighted input will be spread, and its net input will be sqrt(- $\log (.5)$ ) (or 0.8326). Therefore its output will be 0.5 .

The second layer also has as many neurons as input/target vectors, but here $\operatorname{LW}\{2,1\}$ is set to $T$. Suppose you have an input vector $\mathbf{p}$ close to $\mathbf{p}$ i, one of the input vectors among the input vector/target pairs used in designing layer 1 weights. This input $\mathbf{p}$ produces a layer 1 ai output close to 1 . This leads to a layer 2 output close to $\mathbf{t} i$, one of the targets used to form layer 2 weights. A larger spread leads to a large area around the input vector where layer 1 neurons will respond with significant outputs. Therefore if spread is small the radial basis function is very steep, so that the neuron with the weight vector closest to the input will have a much larger output than other neurons. The network tends to respond with the target vector associated with the nearest design input vector. As spread becomes larger the radial basis function's slope becomes smoother and several neurons can respond to an input vector. The network then acts as if it is taking a weighted average between target vectors whose design input vectors are closest to the new input vector. As spread becomes larger more and more neurons contribute to the average, with the result that the network function becomes smoother.

\subsubsection{Adaptive Neural Fuzzy Inference System}

ANFIS is an adaptive network. An adaptive network is a network of nodes and directional links. Associated with the network is a learning rule - for example back propagation. It's called adaptive because some, or all, of the nodes have parameters which affect the output of the node. These networks are learning a relationship between inputs and outputs. Adaptive networks cover a number of different approaches but for our purpose we will investigate in some detail the method proposed by Jang known as ANFIS. ANFIS approach learns the rules and membership functions. 
Rules: The if-then rules have to be determined somehow. This is usually done by 'knowledge acquisition' from an expert. It is a time consuming process that is fraught with problems.

Membership functions: A fuzzy set is fully determined by its membership function. This has to be determined.

For the training of the network, there is a forward pass and a backward pass. We now look at each layer in turn for the forward pass. The forward pass propagates the input vector through the network layer by layer. In the backward pass, the error is sent back through the network in a similar manner to back-propagation.

\section{PROPOSED WORK}

Images are analyzed using color, texture and shape features. The use of color in plant retrieval is more complicated, so we use some basic color features obtained from the segmented image, to represent the color information. Probably the most important aspect of an object is its shape. We use some of the filters of boundary descriptors to extract the local shape features of flowers. In addition to color and shape, the third core characteristic of an object is its texture. Texture features are extracted using texture filters. The features are obtained from the statistical features of gray level co-occurrence matrix.

Color based segmentation using k-means clustering is used to extract the color features. In this technique, we segment the colors in an automated fashion using the $\mathrm{L}^{*} \mathrm{a} \mathrm{b}^{*}$ color space and k-means clustering. The k-means clustered image is shown in figure 1 .

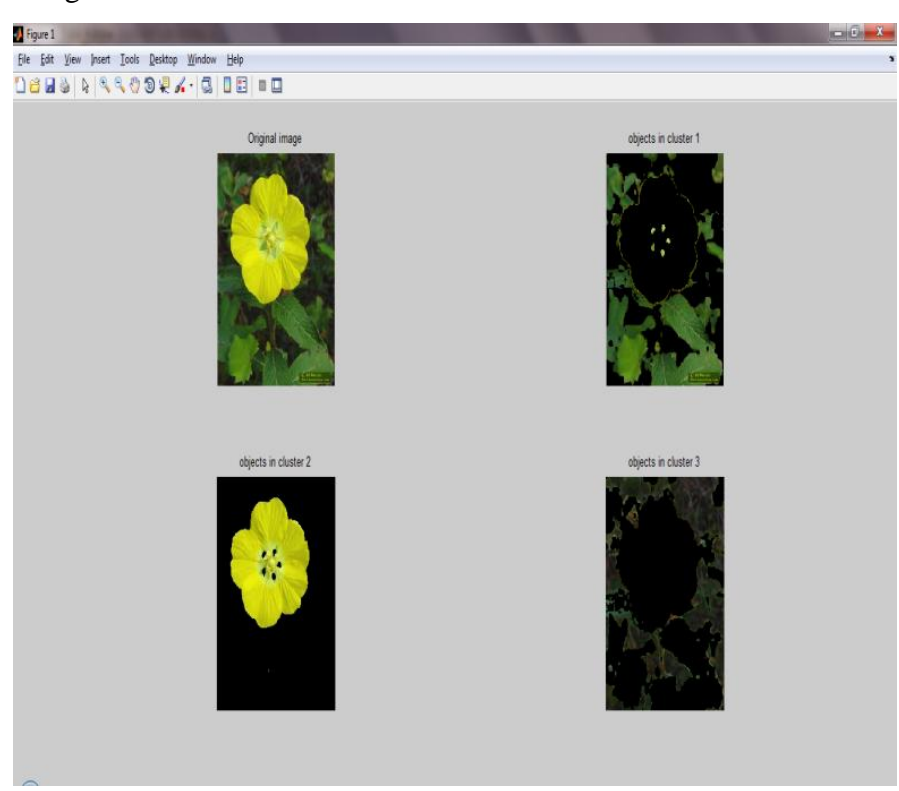

Figure 1: k- means clustered image of ludwigia species

Texture analysis refers to the characterization of regions in the image by their texture content. Texture analysis can be used to find the texture boundaries called texture segmentation. The gray level co-occurrence matrix provides statistics which are used in the species identification. The texture filtered image is shown in Figure 2.

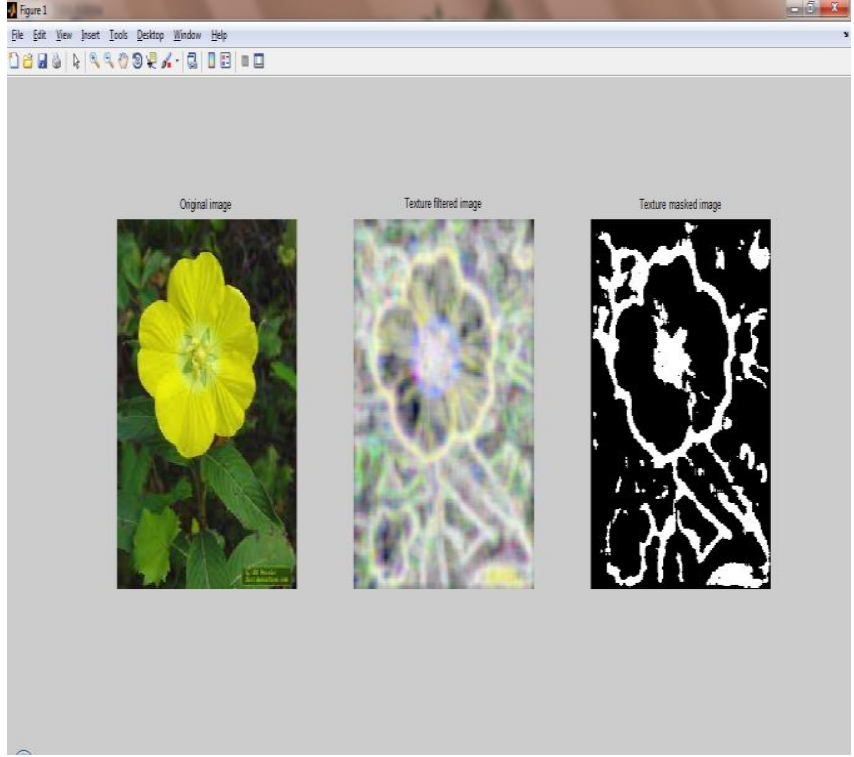

Figure 2: Texture filtered image of ludwigia species

The Sobel, Prewit, Roberts method finds edges using their approximation to the derivative. The mean distance transform for these three filters are extracted for classification. The distance transform is the distance from every pixel to the nearest non-zero valued pixel. The edge detected images are shown in image in Figure 3.

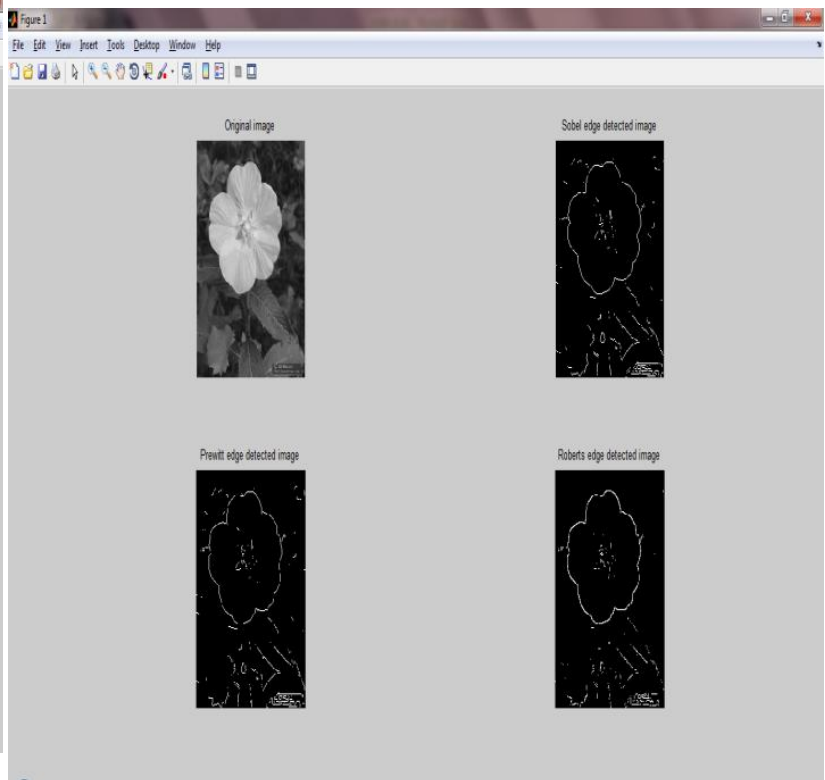

Figure 3: Edge detected images of ludwigia species

Classifications of these plant species are achieved by using four-fold cross validation using GRNN and ANFIS classifiers. These classifications are done for classification of plants in to dry land plants and aquatic plants and aquatic plants into wet (riparian) and shallow standing water (marsh) aquatic plants. The wet aquatic plants are again divided into family Iridiaceae and Epilobium. The marsh aquatic plants are classified as family Malvaceae and Onagraceae. The Iridaceae family is again classified into babiana and crocus species and the Epilobium family into canum and hirsutum. The family Malvaceae is classified into mallow and pavonia while the 
family Onagraceae is classified into fuschia and ludwigia species. The classifiers can be used for classifying the obtained data. The feature vectors are fed into these classifiers for training and testing the data. Figure 4 describes the overall stages of the proposed work.

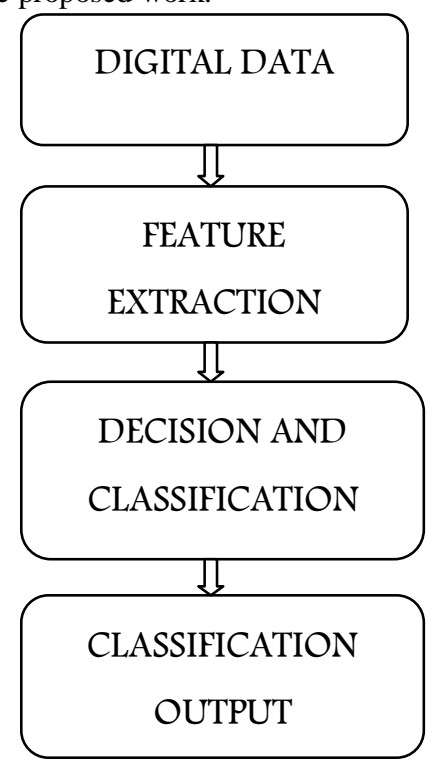

Figure 4: Stages of proposed work

\section{EXPERIMENTAL RESULTS}

The color parameters extracted are mean cluster center (x 1, x2) and standard deviation $(\mathrm{x} 3, \mathrm{x} 4)$ of $\mathrm{a}^{*}$ and $\mathrm{b}^{*}$ color spaces. The gray level co-occurrence matrix provides statistics which are used in the species identification. The texture parameters extracted are contrast (x5), correlation (x6), energy (x7), homogeneity (x8) and entropy (x9). The Sobel (x10), Prewit (x11), Roberts (x12) method finds edges using their approximation to the derivative. The mean distance transform for these three filters are extracted for classification.

Classification of these plant species is achieved by using the 4 fold cross validation using GRNN and ANFIS classifiers. Table 5 shows the performances given by the GRNN and ANFIS classifiers for classification of plants.

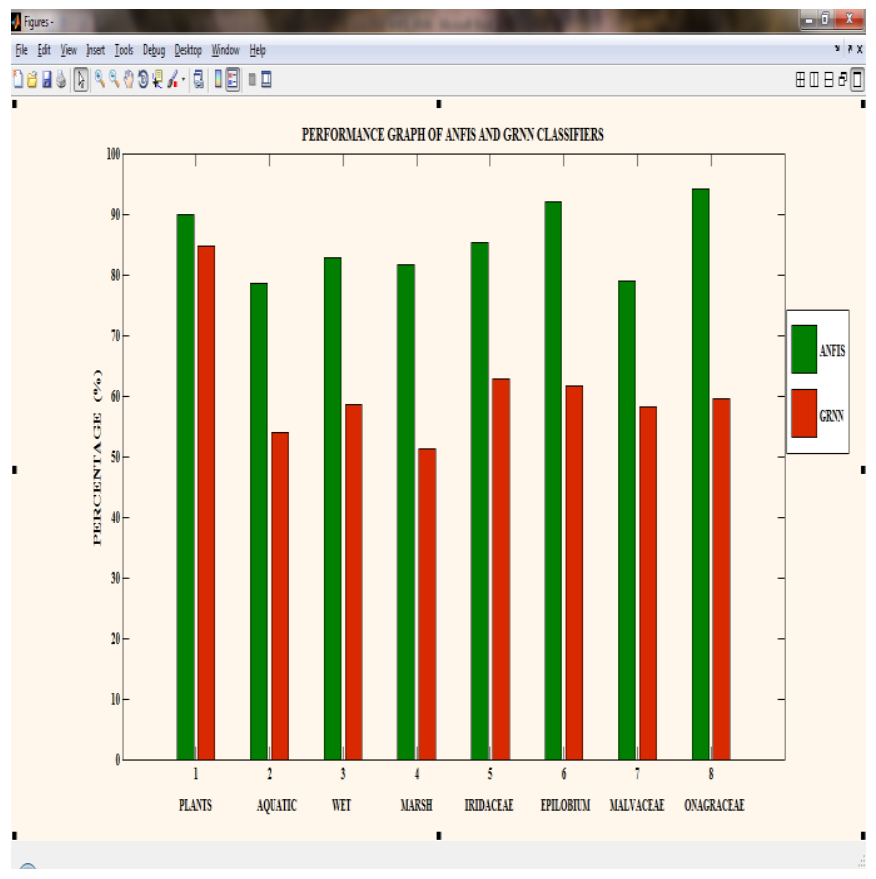

Figure 5: Performance graph of classification of plants by classifiers

\section{CONCLUSIONS}

Training and test data are prepared by 4 fold cross validation.100 training samples and 50 test samples are considered.

In the classification of plants into dry and aquatic plants, an accuracy of $84.63 \%$ was obtained with the GRNN classifier while an accuracy of $89.88 \%$ was obtained with the ANFIS classifier. The accuracy obtained in the further classifications, such as classification of aquatic plants into wet and marsh plants and then into the mentioned families is tabulated in Table 5. It is concluded that these models are capable of producing the target output values with minimal error. ANFIS performs better compared with GRNN for all classification of plants.

\section{SCOPE FOR FUTURE WORK}

In the future work, other features of flowers can be extracted and the extracted features can be modeled by other techniques such as Backpropagation Neural Network (BPNN), Auto Associative Neural Network (AANN) and genetic algorithms to see the further improvements in their performance. Then performances of different classifiers can be compared.

Table 5: Performances of classification of plants by classifiers

\begin{tabular}{|l|c|c|c|c|c|c|c|c|}
\hline CLAS- & PLANTS & $\begin{array}{c}\text { AQUATIC } \\
\text { SIFIERS }\end{array}$ & $\begin{array}{c}\text { WET } \\
(\boldsymbol{\%})\end{array}$ & $\begin{array}{c}\text { MARSH } \\
(\boldsymbol{\%})\end{array}$ & $\begin{array}{c}\text { IRIDA- } \\
(\boldsymbol{\%})\end{array}$ & $\begin{array}{c}\text { EPILOB- } \\
\text { CEAE } \\
(\boldsymbol{\%})\end{array}$ & $\begin{array}{c}\text { MALVEAC } \\
(\boldsymbol{\%})\end{array}$ & $\begin{array}{c}\text { ONAGRACEAE } \\
\text {-EAE } \\
(\boldsymbol{\%})\end{array}$ \\
\hline GRNN & 84.63 & 53.89 & 58.61 & 51.33 & 62.75 & 61.68 & 58.14 & 59.52 \\
\hline ANFIS & 89.88 & 78.50 & 82.73 & 81.64 & 85.28 & 91.98 & 79.01 & 94.18 \\
\hline
\end{tabular}




\section{REFERENCES}

[1] Hanife Kebapci, Berrin Yanikoglu and Gozde Unal "Plant Image Retrieval Using Color, Shape and Texture Features" Faculty of Engineering and Natural Sciences, Sabanci University, Istanbul, Turkey. The Computer Journal Advance Access published April 9, 2010.

[2] Lei Zhang, Jun Kong, Xiaoyun Zeng, Jiayue Ren, "Plant Species Identification Based on Neural Network" Fourth International Conference on Natural Computation. IEEE Computer Society, vol. 5, pp. 90-94, 2008.

[3] B.Sathya Bama, S.Mohana Valli, S.Raju ,V.Abhai, "Content Based Leaf Image Retrieval (CBLIR) Using Shape, Color and Texture Features". Indian Journal of Computer Science and Engineering (IJCSE), vol. 2, no. 2, pp. 202-211, Apr-May 2011.

[4] Norma Jean Venable Illustrated by Ann Payne "AQUATIC PLANTS- Guide to Aquatic and Wetland Plants of West Virginia", Cooperative Extension Service West Virginia University Extension and Public Service series 803, May/June, 1914

[5] Jiazhi Pan, Hangzhou, Zhejiang panjz "Recognition of plants by leaves digital image and neural network" Yong He Biosystem Engineering and Food Science College, Zhejiang University, pp: 906-910, Dec 2008.

[6] Ma W. Y., Yining Deng, and Manjunath B. S., "Tools for texture/color based search of images" Department of Electrical and Computer Engineering, University of California, Santa Barbara, SPIE Int. Conf. 3106, Human Vision and Electronic Imaging II, pp 496-507, Feb. 1997.

[7] Hong Fu., Zheru Chil, Dagan Fengl, and Jiatao Song.J, "Machine Learning Techniques for Ontology-based Leaf Classification" 8th International Conference on Control, Automation, Robotics and Vision Kunming, China, vol: 1, pp: 681-686, 6-9th December 2004.

[8] David R. Martin, Charless C. Fowlkes, and Jitendra Malik "Learning to Detect Natural Image Boundaries Using Local Brightness, Color, and Texture Cues", IEEE transactions on pattern analysis and machine intelligence, vol. 26, no. 5, pp: 530-549, May 2004.
[9] Hhuang Lin, He Peng, "Machine Recognition for BroadLeaved Trees Based on Synthetic Features of Leaves Using Probabilistic Neural Network" International Conference on Computer Science and Software Engineering, pp: 871-877, 2008.

[10] Krishna Singh, Indra Gupta, Sangeeta Gupta, "SVM-BDT PNN and Fourier Moment Technique for of Leaf Shape" International Journal of Signal Processing, Image Processing and Pattern Recognition, vol. 3, no. 4, December, pp. 67-78, 2010.

[11] Corinna Cortes, Vladimar Vapnik, Editor: Lorenza Saitta, "Support-Vector Networks" Machine Learning, Kluwer Academic Publishers, Boston. Manufactured in The Netherlands. AT\&T Bell Labs, Holmdel, vol. 20, pp. 273 297, USA, 1995.

[12] Rahmadhani M. and Yeni Herdiyeni "Shape and Vein Extraction on Plant Leaf Images Using Fourier and BSpline Modeling”, AFITA International Conference, the Quality Information for Competitive Agricultural Based Production System and Commerce, pp. 306-310, 2010.

[13] Jyh-Shing, Roger Jang, ANFIS: "Adaptive-NetworkBased Fuzzy Inference System" IEEE transactions on systems, man and Cybernetics, vol. 23, no. 3, pp. 665-685, May/June 1993.

[14] Chuan-Min Zhai and Ji-Xiang Du, "Applying Extreme Learning Machine to Plant Species Identification", Proceedings of the IEEE International Conference on Information and Automation, Zhangjiajie, China, pp: 879884. June 20 -23, 2008.

[15] Matlab Image Processing Toolbox ${ }^{\mathrm{TM}} 7$ User's Guide, Version 7.2 (Release 2011a).

[16] Rafael C. Gonzalez, Richard E. Woods, "Digital Image Processing using Matlab". PHI learning Private Limited, New Delhi, 2008.

[17] Chih-Wei Hsu, Chih-Chung Chang, and Chih-Jen Lin, "A Practical Guide to Support Vector Classification" Department of Computer Science, National Taiwan University, $\quad$ Taipei, $\quad$ April 2010 